\title{
PERENCANAAN BALOK TRANSFER PRATEGANG (Prestressed transfer Beam)
}

\author{
Dedi Setiadi , Prihantono, Dadang Suyadi Suryasumirat
}

\begin{abstract}
This design is supposed to produced prestressed transfer beam analyze that overcome the massive load of coloum, massive load of beam that caused of center room without coloum. It is design to required the wide room of under floor of building construction. This final project analyze is redesign of transfer beam at project of industry hotel that design using manual analyze beam. Building structure is 9 floor af mesh concrete that design for hotel utility. Transfer beam was located at $5^{\text {th }}$ floor of the building that will use for function hall and the room size $32 \times 25.4 \mathrm{~m}^{2}$.

Technical design base on the real data's of project industry hotel and it will be analyze and design using elastic theory design by T. Y Lin, with technical mechanics using portal ekivalen theory and standard strand from VSL. The beam stressing that cause by the loads of transfer beam will be checked by manual and then will be rechecked using structure program SAP 2000.

Output of this design is $80 \times 120 \mathrm{~cm}$ of prestressed transfer beam with 4 tendon which consist of 2ScU5 - 12 and 2ScU5 - 16, with maximum stress on service condition is $7.10 \mathrm{MPa}$ and lower stress maximum on dimension beam is $+0.96 \mathrm{MPa}$. The stress that happen on dimension beam is still in the limit that allowed (-15.21 MPa for compression and +2.91 MPa for tension).

The conclusion of this design is prestressed transfer beam be able to keep massive load of coloum with tension of the cable prestressed of beam, so the room can be free from coloum can be required.
\end{abstract}

Keyword : prestressed transfer beam

\section{PENDAHULUAN}

Kebutuhan akan ruang serbaguna yang luas pada bangunan bertingkat sangatlah diperlukan, ruangan yang luas ini biasanya digunakan sebagai ruang serbaguna (function hall), tempat pertemuan dan kegiatan lainnya yang melibatkan banyak orang. Dengan

Dedi Setiadi

Alumnus Jurusan Teknik Sipil

Fakultas Teknik

Universitas Negeri Jakarta, 13220
Prihantono, Drs., ST.

Staf Pengajar Jurusan Teknik Sipil Fakultas Teknik

Universitas Negeri Jakarta, 13220
Dadang Suyadi Sumirat, MPd

Staf Pengajar Jurusan Teknik Sipil

Fakultas Teknik

Universitas Negeri Jakarta, 13220 
adanya ruangan yang luas, maka kegiatan yang akan dilakukan oleh pengguna bangunan menjadi leluasa dan mampu menampung banyak orang. Untuk menciptakan ruang yang luas tersebut biasanya dipenuhi dengan cara menghilangkan sebagian kolom, terutama kolom bagian tengah ruangan tersebut.

Peniadaan kolom pada tengah bentang balok dapat menimbulkan beban yang cukup besar pada balok di bawahnya. Besarnya beban yang terjadi pada balok ini diakibatkan karena adanya gaya yang sangat besar dari kolom yang langsung menumpu pada balok tersebut, sehingga balok pada bentang tersebut harus mampu menahan dan mentransfer beban tersebut ke kolom samping secara merata. Balok yang memikul beban yang sangat besar ini biasanya disebut dengan balok transfer (transfer beam).

Akibat adanya beban yang besar pada balok transfer tersebut biasanya dimensi balok pada desain untuk daerah transfer sangat besar dan untuk membantu menahan beban yang sangat besar pada balok tersebut, biasanya struktur balok tersebut diberi gaya prategang (prestress).

Kekhususan perhitungan transfer beam terletak dalam perencanaan untuk menentukan besarnya gaya-gaya yang terjadi pada balok transfer yang terletak di bawahnya, dimana harus diusahakan agar beban yang besar tersebut dapat terdistribusi secara merata melalui kolom-kolom yang ada di bawah balok transfer tersebut. Jika beban-beban yang ada sudah terdistribusi secara merata, selanjutnya perhitungan sı seperti balok biasa. Perbedaanya hanya pada besarnya beban yang bekerja pada ben balok.

Penggunaan beton sebagai bahan struktur yang diberi gaya prategang baik pada pelat lantai maupun balok adalah merupakan pemecahan dan pilihan yang mungkin untuk dilakukan. Sistem prategang secara sederhana dapat didefinisikan sebagai pemberian beban imbang (balance load) pada suatu struktur dimana cara kerja beton prategang adalah mengkombinasikan beton berkekuatan tinggi dengan baja mutu tinggi, dimana beton ditransformasikan dari bahan yang getas menjadi bahan yang elastis dengan cara memberikan tekanan terlebih dahulu pada bahan tersebut.

Bahan beton seperti telah banyak diketahui tidak mampu menahan tarikan, akan tetapi kuat menahan tekanan. Pada beton prategang beton dikondisikan sedemikian rupa sehingga bahan yang getas dapat menahan tegangan tarik. Hal ini dilakukan dengan cara menarik baja berkekuatan tinggi dan menahankannya ke beton mutu tinggi, sehingga 
membuat beton dalam keadaan tertekan yang kemudian dapat dimanfaatkan untuk mengimbangi tegangan tarik yang terjadi akibat adanya pembebanan pada struktur. Jadi beton prategang merupakan kombinasi yang ideal dari dua bahan yang memiliki kekuatan tinggi. Oleh karena itu penggunaan beton prategang pada saat ini telah banyak digunakan, seperti pada jembatan, tanki, pondasi tiang dan gedung-gedung tinggi.

Pada struktur prategang yang terdiri dari batang-batang satu arah seperti balok menerus, kontraksi aksial akibat pengaruh prategang tidak berpengaruh pada gaya dan momen struktur. Hal ini berbeda dengan struktur rangka portal yang arah batangbatangnya berlainan, pemberian gaya prategang pada balok mendatar rangka portal akan menghasilkan suatu kontraksi aksial yang akan menghasilkan momen tersier ke dalam portal rangka akibat adanya pergeseran lateral pertemuan balok mendatar dan batang kolom. Sehingga perlu diperhitungkan pengaruh deformasi aksial pada struktur portal yang diberikan gaya prategang.

Skripsi ini akan membahas mengenai usaha untuk memenuhi permintaan akan ruang luas dan bebas kolom dengan penggunaan balok transfer prategang (prestressed transfer beam) yang merupakan studi kasus pada pembangunan Hotel Industri. Ruangan tersebut terdapat di lantai tiga dan empat pada hotel industri Jakarta, dengan letak balok transfer pada As. D8 - D10. Perhitungan yang dilakukan pada skripsi ini merupakan perhitungan kembali (redesign) dari data-data proyek yang ada di lapangan. Pembahasan ini meliputi peninjauan terhadap balok beton transfer yang memikul gaya yang sangat besar dari kolom struktur yang langsung berdiri pada bentangnya dan aksi kolom akibat pemberian gaya prategang. Untuk mempermudah perhitungan akan digunakan program adapt (SAP 2000), karena selain menjadi lebih cepat perhitungan juga harus dicoba berkali-kali untuk mendapatkan jumlah tendon yang diperlukan sehingga tidak melewati tegangan izin baik dalam keadaan transfer maupun dalam keadaan service.

Perencanaan ini diharapkan dapat memberikan gambaran kepada pemakai atau masyarakat terhadap penggunaan balok beton prategang pada daerah transfer beam. Selain itu sebagai tambahan pengetahuan bagi mahasiswa Jurusan Teknik Sipil UNJ, khususnya untuk mata kuliah Struktur Beton Prategang. Sedangkan bagi penulis, perencanaan transfer beam ini dapat memperdalam perhitungan struktur gedung dan 
perencanaan balok beton prategang, juga sebagai salah satu syarat kelulusan sarjana pada Program Studi Teknik Sipil UNJ.

\section{METODA}

Struktur gedung adalah konstruksi beton bertulang berjumlah 9 lantai yang direncanakan untuk keperluan hotel. Balok transfer terdapat di Lt. 5 yang akan digunakan untuk function hall dengan luas ruangan $32 \times 25.4 \mathrm{~m}^{2}$. Untuk lebih jelasnya dapat dilihat pada gambar 18, gambar 19 dan gambar 20.

Dimensi kolom pada portal yang di analisa adalah $(60 \times 70) \mathrm{cm}^{2}$ untuk lantai 6 sampai dengan lantai 9. Untuk lantai 1 sampai dengan lantai 5 akan direncanakan memakai $(80 \times 80) \mathrm{cm}^{2}$ kecuali untuk kolom yang menahan balok transfer, akan dipakai $(100 \times 100) \mathrm{cm}^{2}$. Sedangkan dimensi balok dalam arah $x$ dan arah y adalah $(30 \times 70) \mathrm{cm}^{2}$, kecuali untuk dimensi balok pada atap adalah $(30 \times 60) \mathrm{cm}^{2}$. Untuk balok yang panjang dan memikul beban luar yang besar maka akan digunakan balok prestressed yang akan di rencanakan dalam bahasan lebih lanjut. Tebal pelat $15 \mathrm{~cm}$ untuk lantai dan $12 \mathrm{~cm}$ untuk atap.

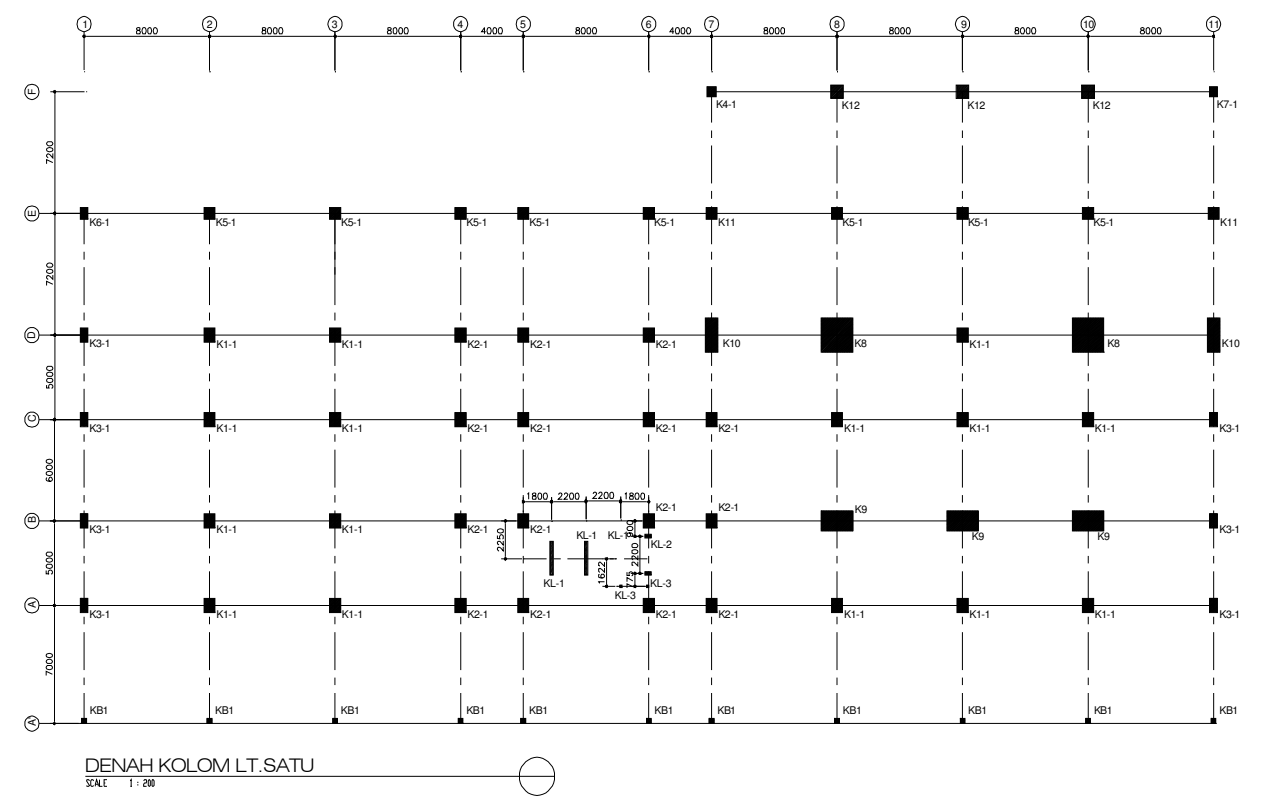

Gambar 1. Denah struktur bangunan lantai. 1 


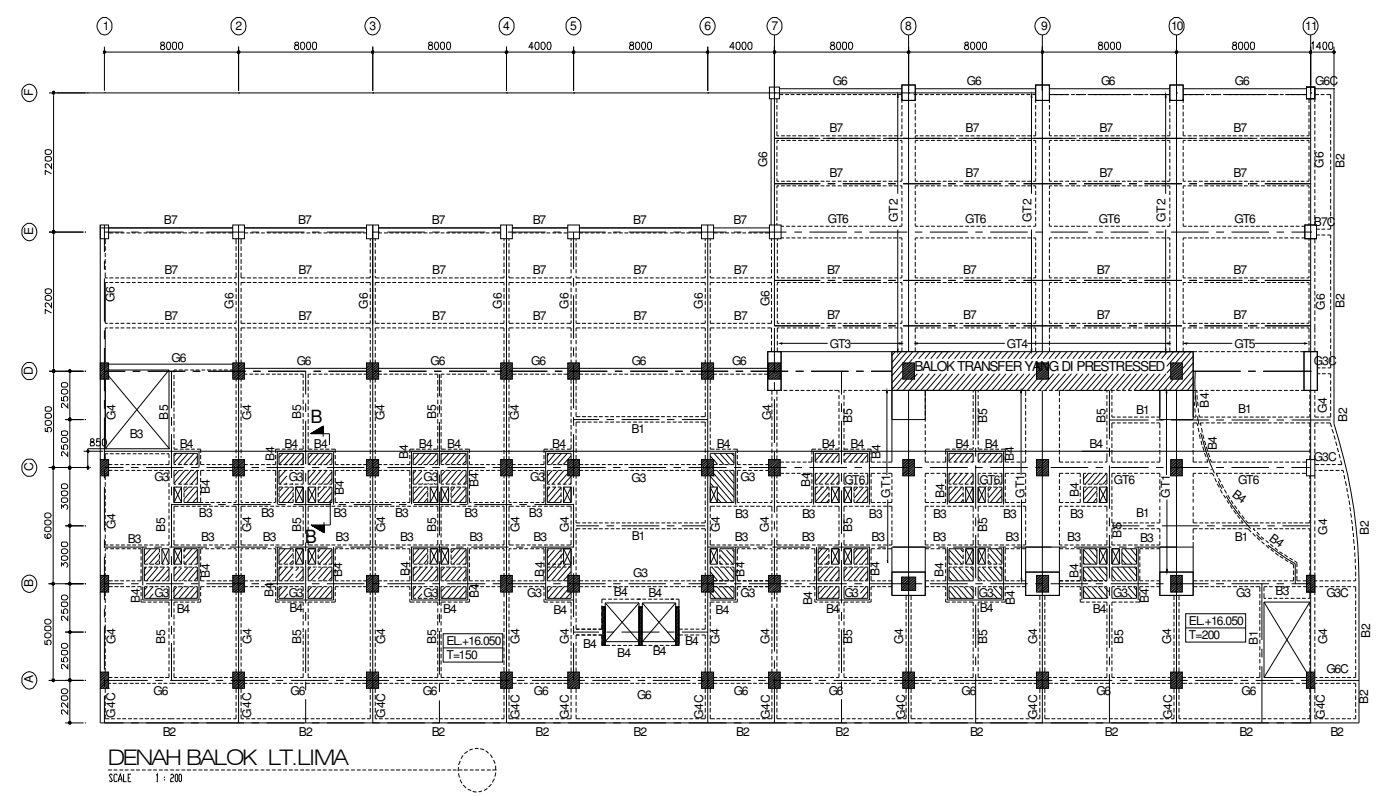

Gambar 2. Denah balok lantai. 5 (Balok transfer)

Dimensi kolom pada portal di mana terdapat balok prestress dapat dilihat pada gambar tampak samping bangunan di bawah ini

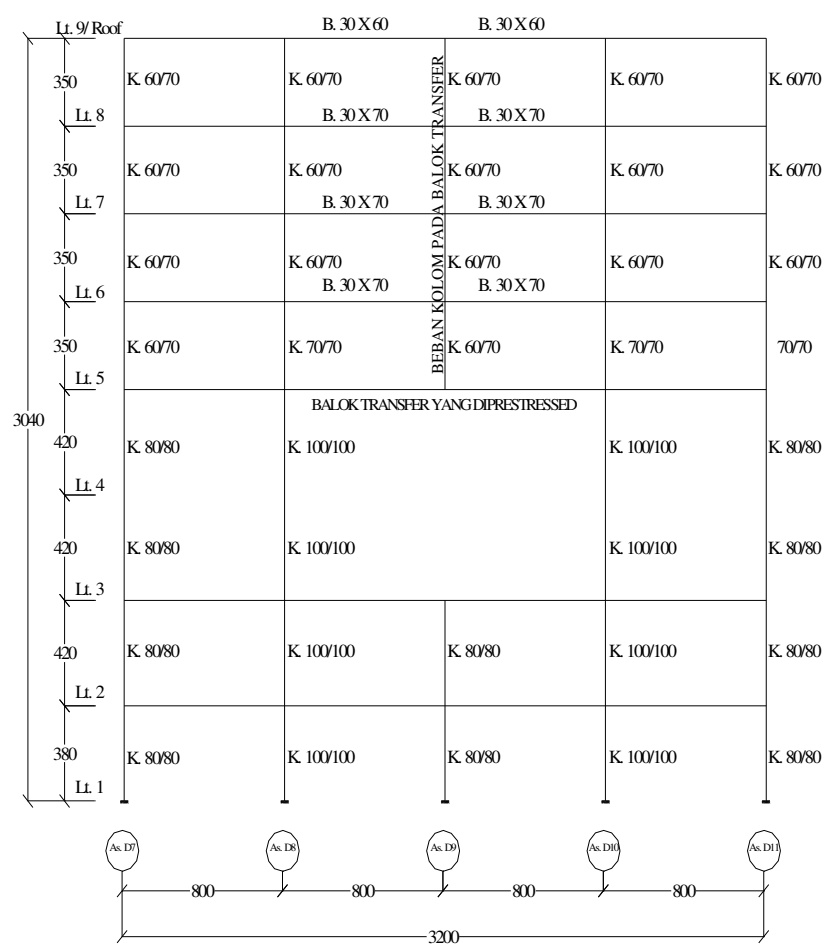

Gambar 3. Portal D- D 


\section{Data Desain :}

1. Material :

a. Mutu beton yang akan digunakan untuk balok adalah : K-400

b. Strand (Standar VSL)

Seven wire stress-relieve uncoated strand according to ASTM A416-90 Grade 270

Low relaxation

Nominal diameter $12.7 \mathrm{~mm}$

Nominal steel area $98.71 \mathrm{~mm}^{2}$

Minimum ultimate tension strength 18733 kgf

$(183.7 \mathrm{kN})$

Minimum yield tension strength $16860 \mathrm{kgf}(165.3 \mathrm{kN})$

Nominal modulus elasticity $1.9 \mathrm{E}+06 \mathrm{~kg} / \mathrm{cm}^{2}$

$(196 \mathrm{E}+03 \mathrm{MPa})$

c. Tulangan non prategang memakai baja $f_{y}=400 \mathrm{MPa}$

d. Duct (Standar VSL) Material ini berfungsi sebagai

pembungkus strand. Berupa pipa berulir dengan diameter :

\begin{tabular}{|c|c|}
\hline Diameter Duct & Jumlah Strand \\
\hline $63 \mathrm{~mm}$ & 12 \\
\hline $84 \mathrm{~mm}$ & 19 \\
\hline
\end{tabular}

e. Angkur (Sistem VSL)

\begin{tabular}{|c|c|c|}
\hline Angkur Hidup & Angkur Mati & Jumlah Strand \\
\hline $12 \mathrm{Sc}$ & $12 \mathrm{U}$ & 12 \\
\hline $19 \mathrm{Sc}$ & $19 \mathrm{U}$ & 19 \\
\hline
\end{tabular}

f. $E_{c \text { beton }}=\left(W_{c}\right)^{1.5} \times 0.03973 \times \sqrt{f_{c}^{\prime}}(\mathrm{kN} / \mathrm{mm})$

$$
\mathrm{E}_{\mathrm{c} \text { beton }}=\left(\mathrm{W}_{\mathrm{c}}\right)^{1.5} \times 0.043 \times \sqrt{f_{c}^{\prime}}(\mathrm{Kg} / \mathrm{cm})
$$

2. Pembebanan: a. Berat jenis beton $24 \mathrm{kN} / \mathrm{m}^{3}$

b. Beban hidup : $2.5 \mathrm{kN} / \mathrm{m}^{2}$ pada lantai

$1 \mathrm{kN} / \mathrm{m}^{2}$ pada atap

c. Beban mati tambahan ADL (finishing, partisi, ceiling,

mechanical \& electrical) : $1.5 \mathrm{kN} / \mathrm{m}^{2}$ 

d. Beban lateral statik tidak diperhitungkan
e. Beban gempa tidak diperhitungkan

3. Data lain :
a. Koefisien Wobble $(K)=0.0030 / \mathrm{m}$
b. Koefisien geser angular $=0.20 / \mathrm{rad}$
c. Desain tendon menurut peraturan VSL
d. Penarikan kabel secara bertahap

\section{HASIL DAN PEMBAHASAN}

\section{Desain Pendahuluan}

1. Modulus elastisitas beton

Pada kasus ini perlu memperhatikan kekuatan beton yang dicapai pada saat penarikan awal terjadi, hal ini dilakukan agar tidak merusak bagian beton pada ujung-ujung penjangkaran.

Perbedaan umur beton disini mengakibatkan terjadinya perbedaan pada modulus elastisitas beton. Modulus elastisitas dianggap mencapai kekuatannya sebesar 100\% apabila umur beton telah mencapai 28 hari atau lebih. Pada tugas akhir ini ditetapkan umur saat penarikannya adalah : penarikan awal direncanakan pada umur 10 hari.

2. Mutu beton $\mathrm{K}-400$

$$
\begin{aligned}
f^{\prime}{ }_{c} & =\left[0.76+0.2 \log \frac{\sigma_{b k}^{\prime}}{15}\right] \sigma_{b k}^{\prime} \\
& =\left[0.76+0.2 \log \frac{40}{15}\right] 40 \\
& =33.8 \mathrm{MPa} \\
\mathrm{f}^{\prime}{ }_{\mathrm{ci}} & =0.8 \mathrm{f}_{\mathrm{c}}^{\prime} \\
& =27.04 \mathrm{MPa}
\end{aligned}
$$


Tegangan izin beton prestress :

Segera setelah transfer/ awal

$$
\begin{array}{lll}
\text { Tekan }: 0.60 \mathrm{f}_{\mathrm{ci}}^{\prime} & =16.22 \mathrm{MPa} \\
\text { Tarik }: 0.25 \sqrt{\mathrm{f}^{\prime}{ }_{\mathrm{ci}}} \quad=1.3 \mathrm{Mpa}
\end{array}
$$

Pada saat service

$$
\begin{aligned}
& \text { Tekan : } 0.45 \mathrm{f}^{\prime}{ }_{\mathrm{ci}} \quad=15.21 \mathrm{MPa} \\
& \text { Tarik : } 0.50 \sqrt{\mathrm{f}_{\mathrm{ci}}^{\prime}} \quad=2.91 \mathrm{MPa}
\end{aligned}
$$

3. Mutu baja prategang

Di mana : $f_{\text {pu }}=1860 \mathrm{MPa}$ (kekuatan baja ultimate)

$$
\mathrm{f}_{\mathrm{e}}=1000 \mathrm{MPa} \text { (kekuatan baja efektif rata-rata) }
$$

menggunakan 7 wire strands diameter $12.7 \mathrm{~mm}\left(A=98.71 \mathrm{~mm}^{2}\right)$

Tegangan izin baja :

Kekuatan baja segera setelah pengangkuran :

$$
\begin{aligned}
\mathrm{f}_{\mathrm{i}} & =0.70 \mathrm{f}_{\mathrm{pu}} \\
& =0.70 \times 1860 \\
& =1302 \mathrm{MPa}
\end{aligned}
$$

Kekuatan baja pada saat penarikan/ Jacking :

$$
\begin{aligned}
\mathrm{f}_{\mathrm{i}} & =0.80 \mathrm{f}_{\mathrm{pu}} \\
& =0.80 \times 1860 \\
& =1488 \mathrm{MPa}
\end{aligned}
$$

\section{Perencanaan awal (Pre eliminary design)}

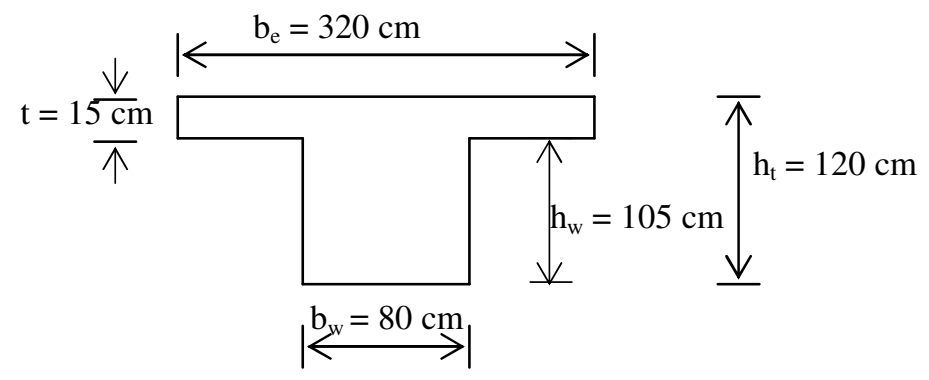

$$
\begin{aligned}
\text { Ac } & =(80 \times 105)+(15 \times 320) \\
& =13200 \mathrm{~cm}^{2}=1.32 \mathrm{~m}^{2}
\end{aligned}
$$


Statis Momen

$$
\begin{aligned}
& \mathrm{c}_{\mathrm{b}}= \frac{(80 \times 105) 52.5+(320 \times 15) 112.5}{(80 \times 105)+(320 \times 15)} \\
&= 74.32 \mathrm{~cm}=0.7432 \mathrm{~m} \\
& \mathrm{C}_{\mathrm{t}}=120-74.32 \\
&=45.68 \mathrm{~cm}=0.4568 \mathrm{~m} \\
& \mathrm{I}_{\mathrm{x}}=\frac{1}{12} \times 0.8 \times 1.05^{3}+\frac{1}{12} \times 3.2 \times 0.15^{3}+(0.8 \times 1.05)(0.7432-0.525)^{2}+ \\
&(3.2 \times 0.15)(0.4568-7.5)^{2} \\
&= 0.1880386368 \mathrm{~m}^{4}
\end{aligned}
$$

Jarak kern atas ke c. g. c

$$
\begin{aligned}
k_{t} & =\frac{I_{x}}{A_{c} C_{b}} \\
& =\frac{18803863.68}{(13200 \times 74.32)}=19.17 \mathrm{~cm}=0.1917 \mathrm{~m}
\end{aligned}
$$

Jarak kern bawah ke c. g. c

$$
\begin{aligned}
\mathrm{k}_{\mathrm{b}} & =\frac{\mathrm{I}_{\mathrm{x}}}{\mathrm{A}_{\mathrm{c}} \mathrm{C}_{\mathrm{t}}} \\
& =\frac{18803863.68}{(13200 \times 45.68)}=31.18 \mathrm{~cm}=0.3118 \mathrm{~m}
\end{aligned}
$$

Perbandingan $\mathrm{M}_{\mathrm{G}} / \mathrm{M}_{\mathrm{T}} \quad=\frac{784.34}{3734.82}=21 \%>20 \%$

Karena perbandingan $\mathrm{M}_{\mathrm{G}}$ lebih besar dari $20 \% \mathrm{M}_{\mathrm{T}}$, maka desain pendahuluan ditentukan oleh $\mathrm{M}_{\mathrm{T}}$.

Gaya prategang efektif : 


$$
\mathrm{F}=\frac{\mathrm{M}_{\mathrm{T}}}{0.65 \mathrm{~h}}=\frac{3734.82}{0.65 \times 1.2}=4788.23 \mathrm{kN}
$$

Akan tetapi, karena $\mathrm{M}_{\mathrm{G}}$ dan $\mathrm{M}_{\mathrm{T}}$ telah diketahui, maka akan di coba dengan $\mathrm{F}$ dengan menggunakan $\mathrm{ML}$

$$
\mathrm{F}=\frac{\mathrm{M}_{\mathrm{T}}-M_{G}}{0.50 \mathrm{~h}}=\frac{3734.82-784.34}{0.50 \times 1.2}=4917.47 \mathrm{kN}
$$

Dipilih gaya prategang yang paling besar yaitu berdasarkan Mı sebesar 4917.47 kN.

Dengan menganggap loss sebesar $15 \%$, maka :

$$
\mathrm{F}_{\mathrm{o}}=\frac{\mathrm{F}}{85 \%}=\frac{4917.47}{0.85}=5785.25 \mathrm{kN}
$$

$$
\begin{aligned}
f_{\text {se }} & =85 \% \times f_{p i} \\
& =1106.7 \mathrm{~N} / \mathrm{mm}^{2}
\end{aligned}
$$

Sehingga $A_{p s}=\frac{F}{f_{s e}}=\frac{5785.25 \times 10^{3}}{1106.7 \times 10^{6}}=0.00523 \mathrm{~m}^{2}$

Penentuan eksentrisitas c. g. s terhadap c. g. c

$$
\begin{aligned}
\mathrm{e}_{1} & =\frac{\mathrm{f}_{\mathrm{t}}^{\prime} \times \mathrm{A}_{\mathrm{c}} \times \mathrm{k}_{\mathrm{b}}}{\mathrm{F}_{\mathrm{o}}} \\
& =\frac{0.25 \sqrt{27.04 \times 10^{2}} \times 13200 \times 31.18}{5785.25 \times 10^{3}} \\
& =0.92485 \mathrm{~cm} \\
\mathrm{e}_{2} & =\frac{\mathrm{M}_{\mathrm{G}}}{\mathrm{F}_{\mathrm{o}}} \\
& =\frac{784.34 \times 10^{2}}{5785.25} \\
& =13.5576 \mathrm{~cm} \\
\mathrm{e}_{1}+\mathrm{e}_{2}= & 14.48 \mathrm{~cm} \\
\text { Jadi e }= & \mathrm{k}_{\mathrm{b}}+\left(\mathrm{e}_{1}+\mathrm{e}_{2}\right) \\
= & 31.18+14.48 \\
= & 45.66 \mathrm{~cm}<\mathrm{c}_{b}(74.32 \mathrm{~cm})
\end{aligned}
$$

Penentuan kembali gaya prategang efektif : 


$$
\begin{aligned}
\mathrm{F} & =\frac{\mathrm{M}_{\mathrm{T}}-\mathrm{f}_{\mathrm{b}}^{\prime} \times \mathrm{Ac}_{\mathrm{k}} \mathrm{k}_{\mathrm{t}}}{\mathrm{e}+\mathrm{k}_{\mathrm{t}}} \\
& =\frac{3734.8 \times 10^{5}-0.5 \sqrt{3380} \times 13200 \times 19.17}{45.13+19.17} \\
& =5647.45 \mathrm{kN} \\
\mathrm{F}_{\mathrm{o}} & =\frac{\mathrm{F}}{85 \%}=\frac{5647.45}{0.85}=6644.06 \mathrm{kN}
\end{aligned}
$$

Cek penampang untuk kondisi penarikan awal

$$
\begin{aligned}
A_{c} & =\frac{F_{o} \times h}{f_{b} \times c_{t}-f_{t}^{\prime} \times c_{b}} \\
& =\frac{6644.06 \times 120 \times 1000}{0.6 \times 2704 \times 45.68-0.25 \sqrt{2704} \times 74.32} \\
& =10900.08 \mathrm{~cm}^{2}<\text { Ac Prarencana }\left(13200 \mathrm{~cm}^{2}, \text { ok }\right)
\end{aligned}
$$

Dengan demikian nilai eksentrisitas dapat dipakai. Akan tetapi agar diperoleh harga momen maksimum yang dapat dipikul oleh penampang, maka diusahakan lengan momennya sejauh mungkin dari c. g. c. Hal ini dilakukan dengan cara meletakan kabel sedekat mungkin dengan serat penampang, diambil $15 \mathrm{~cm}$ dari serat bawah.

Dengan memperkirakan pemakaian strand : $\frac{52.3 \mathrm{~cm}^{2}}{1 \mathrm{~cm}^{2}}=53$ strand, maka dengan memakai 4 tendon yang dibagi dalam 2 baris terdiri dari 2 tendon di atas dan 2 tendon di bawah, serta selimut beton.

5. Cek penampang

a. Transfer :

$$
\begin{aligned}
A_{c} & =\frac{F_{o} \times h}{f_{b} \times c_{t}-f_{t}^{\prime} \times c_{b}} \\
& =\frac{6644.06 \times 120 \times 1000}{0.6 \times 2704 \times 45.68-0.25 \sqrt{2704} \times 74.32} \\
& =10900.08 \mathrm{~cm}^{2}<\text { Ac Prarencana }\left(13200 \mathrm{~cm}^{2}, \text { ok }\right)
\end{aligned}
$$


b. Service :

$$
\begin{aligned}
A_{c}=\frac{F x h}{f_{t} c_{b}-f^{\prime}{ }_{b} c_{t}} & =\frac{5647.45 \times 120 \times 1000}{0.45 \times 3380 \times 74.32-(0.5 \sqrt{3380 \times 45.68})} \\
& =6066.39 \mathrm{~cm}^{2}<\text { Ac Prarencana }\left(13200 \mathrm{~cm}^{2}, \text { ok }\right)
\end{aligned}
$$

Ac terbesar yaitu pada saat transfer $\left(10900.08 \mathrm{~cm}^{2}\right)$ masih lebih kecil dari Ac prarencana (13200 $\left.\mathrm{cm}^{2}\right)$, jadi penampang balok yang direncanakan dapat dipergunakan.

\section{KEHILANGAN GAYA PRATEGANG}

Gaya tarik awal (pra rencana) $\quad=6644.06 \mathrm{kN}$

Kehilangan gaya prategang terdiri atas :

$$
\begin{aligned}
\text { Loss akibat perpendekan elastis } & =22.60 \mathrm{kN} \\
\text { Loss akibat slip pengangkuran } & =861.88 \mathrm{kN} \\
\text { Loss akibat rangkak beton } & =221.20 \mathrm{kN} \\
\text { Loss akibat susut beton } & =67.20 \mathrm{kN} \\
\text { Loss akibat relaksasi baja } & =149.13 \mathrm{kN}+ \\
\text { Total loss } & =1322.01 \mathrm{kN}
\end{aligned}
$$

Dari hasil perhitungan kehilangan gaya prategang, ternyata menghasilkan jumlah loss yang lebih besar dari yang diperkirakan (15\%) yaitu sebesar $19.89 \%$. Untuk selanjutnya akan dihitung $\mathrm{F}$ minimum berdasarkan kehilangan prategang yang telah dihitung, yaitu:

$$
\begin{aligned}
\mathrm{F} \text { minimum } & =6644.06-1322.01 \\
& =5323 \mathrm{kN}>\mathrm{F} \text { rencana awal }(4917.47 \mathrm{kN}) \text {, maka akan } \\
& \text { digunakan } \mathrm{F} \text { minimum. }
\end{aligned}
$$

Penggunaan jumlah strand dalam 1 tendon

Besarnya kehilangan gaya prategang berdasarkan $F_{\text {minimum }}$ : 


$$
\begin{aligned}
& \text { Persentase loss }=\frac{1322.01}{5323} \times 100 \%=24.83 \% \approx 25 \% \\
& \begin{aligned}
\mathrm{f}_{\mathrm{se}} & =(1-0.25) \mathrm{x}_{\mathrm{pi}} \\
& =0.75 \times 1302 \\
& =976.5 \mathrm{~N} / \mathrm{mm}^{2}=0.9765 \mathrm{kN} / \mathrm{mm}^{2}
\end{aligned} \\
& \text { Sehingga : } \mathrm{A}_{\mathrm{PS}}=\frac{\mathrm{F}}{\mathrm{f}_{\mathrm{se}}} \\
& =\frac{5323 \mathrm{kN}}{0.9765 \mathrm{kN} / \mathrm{mm}^{2}}=5451.10 \mathrm{~mm}^{2}=54.51 \mathrm{~cm}^{2}
\end{aligned}
$$

Dengan asumsi 1 strand bisa menerima 10 ton, maka penggunaan strand untuk kasus ini adalah $=\frac{54.51}{9.81}=556$ ton $\approx 56$ strand, dengan demikian akan dipakai jenis strand 2ScU5-12 dan 2ScU5-16, sesuai dengan standar strand VSL.

\section{PENGECEKAN TEGANGAN}

Tegangan yang terjadi pada penampang antara hasil program dengan manual bisa dilihat pada tabel di bawah ini :

\begin{tabular}{|l|l|l|l|l|}
\hline $\mathbf{x}(\mathbf{m})$ & $\begin{array}{l}\sigma_{\mathrm{a}} \mathbf{S A P} \\
\left(\mathbf{N} / \mathbf{m m}^{2}\right)\end{array}$ & $\begin{array}{l}\sigma_{\mathrm{a}} \text { manual } \\
\left(\mathbf{N} / \mathbf{m m}^{2}\right)\end{array}$ & $\begin{array}{l}\sigma_{\mathrm{b}} \mathbf{S A P} \\
\left(\mathbf{N} / \mathbf{m m}^{2}\right)\end{array}$ & $\begin{array}{l}\sigma_{\mathrm{b}} \text { manual } \\
\left(\mathbf{N}^{2} \mathbf{m m}^{2}\right)\end{array}$ \\
\hline 0.80 & -3.46 & -3.46 & -4.96 & -4.97 \\
\hline 1.60 & -3.69 & -3.68 & -4.60 & -4.60 \\
\hline 2.40 & -3.59 & -3.58 & -4.76 & -4.77 \\
\hline 3.20 & -3.64 & -3.63 & -4.67 & -4.68 \\
\hline 4.00 & -3.83 & -3.83 & -4.36 & -4.37 \\
\hline 4.80 & -4.19 & -4.18 & -3.78 & -3.79 \\
\hline 5.60 & -4.68 & -4.68 & -2.97 & -2.98 \\
\hline 6.40 & -5.34 & -5.33 & -1.91 & -1.92 \\
\hline 7.20 & -6.15 & -6.14 & -0.59 & -0.60 \\
\hline 8.00 & -7.10 & -7.10 & 0.96 & 0.95 \\
\hline
\end{tabular}

Hasil perhitungan tegangan untuk kedua perhitungan (manual dan program) yang dilakukan untuk kombinasi berbagai pembebanan, menghasilkan tegangan yang masih dalam batas yang diizinkan untuk penampang beton dalam kondisi service (- 15.21 $\mathrm{N} / \mathrm{mm}^{2}$ untuk tekan dan $+2.91 \mathrm{~N} / \mathrm{mm}^{2}$ untuk tarik). Dengan demikian besarnya gaya 
prategang yang diberikan dan penempatan eksentrisitas kabel pada perhitungan sudah dapat mengimbangi beban luar yang bekerja pada balok transfer

\section{KESIMPULAN}

Dari hasil studi yang dilakukan pada penulisan skripsi ini dapat ditarik kesimpulan sebagai berikut :

1. Balok prestress transfer (transfer beam) mampu memikul transfer gaya yang besar dari kolom dengan melalui penarikan kabel prestress.

2. Deformasi aksial akibat gaya prategang pada kolom relatif sangat kecil sehingga dapat diabaikan, dimana seluruh gaya prategang ditahan oleh balok.

3. Perhitungan atau perencanaan balok prestress secara portal ekivalen memberikan hasil yang cukup diterima. Hal ini dapat dilihat dari tabel perbandingan tegangan yang terjadi berdasarkan jenis pembebananya

\section{DAFTAR PUSTAKA}

Buku Pedoman Perencanaan Untuk Struktur Beton Bertulang Biasa dan Struktur Tembok Beton Bertulang Untuk Gedung. 1983.Bandung : Departemen Pekerjaan Umum RI,

Gunawan. T dan Margaret. S. 2001.Diktat Teori Soal Dan Penyelesaian Konstruksi Beton Pratekan Jilid I. Jakarta : Delta Teknik Group,

Gunawan. T dan Margaret. S. 2006. Diktat Teori Soal Dan Penyelesaian Konstruksi Beton I Jilid I. : Delta Teknik Group, Jakarta

Hardjasaputra, Harianto dan Steffie Tumilar, 2002. Model Penunjang dan Pengikat Pada Perancangan Struktur Beton. : Universitas Pelita Harapan, Jakarta

Hadipratomo, Winarni. 1988. Struktur Beton Prategang : Teori dan Prinsip Desain.

: Nova, Bandung

Lin , T.Y. Ned-H. Burns. 1996.Desain Struktur Beton Prategang Jilid 1. : Erlangga, Jakarta Erlangga,. Jakarta 
2002. Metode, Spesifikasi dan Tata Cara Struktur Bangunan :

Departemen Pemukiman dan

Prasarana Wilayah,

, Metode Kerja Post Tensioning Beam : PT. VSL Indonesia

Nawy, G Edward. 2001. Beton Prategang Suatu Pendekatan Mendasar Jilid 1. Jakarta : Erlangga,

2001. Beton Prategang Suatu Pendekatan Mendasar Jilid 2. :

Erlangga, Jakarta

--a---, 2003. Pedoman Penulisan Skripsi : Teknik Sipil Universitas Negeri

Jakarta,

Raju, N. Krishna. 1988. Beton Prategang. : Erlangga, Jakarta

Schodek, Daniel L. 1999. Struktur. : Erlangga, Jakarta 